\title{
Predictors of contraceptive use among adolescent girls and young women (AGYW) aged 15 to 24 years in South Africa: results from the 2012 national population-based household survey
}

L. Makola ${ }^{1,2^{*}}$ (D, L. Mlangeni ${ }^{3}$, M. Mabaso $^{1}$, B. Chibi ${ }^{1}$, Z. Sokhela' , Z. Silimfe ${ }^{1}$, L. Seutlwadi ${ }^{4}$, D. Naidoo ${ }^{1}$, S. Khumalo ${ }^{5}$, A. Mncadi ${ }^{5}$ and K. Zuma ${ }^{1}$

\begin{abstract}
Background: Despite a variety of contraceptives being available for women in South Africa, a considerable number of adolescent girls and young women still face challenges in using them. This paper examines socio-demographic and behavioral predictors of using contraceptives among adolescent girls and young women (AGYW) aged 15 to 24 years.

Methods: A secondary data analysis was conducted based on the 2012 population-based nationally representative multi-stage stratified cluster randomised household survey. Multivariate backward stepwise logistic regression model was used to examine socio-demographic and behavioural factors independently associated with contraceptive use amongst AGYW aged 15 to 24 years in South Africa.
\end{abstract}

Results: Out of 1460 AGYW, 78\% (Cl: 73.9-81.7) reported using some form of contraceptives. In the model, contraceptive use was significantly associated with secondary education $[\mathrm{OR}=1.8(1.2-2.7), p=0.005]$, having a sexual partner within 5 years of their age $[O R=1.8(1.2-2.5), p=0.002]$, and sexual debut at age 15 years and older $[O R=2.5(1.3-4.6), p=0.006]$. The likelihood of association decreased with other race groups-White, Coloured, and Indians/Asians [OR $=0.5(0.3-0.7)$, $p=0.001$, being married $[\mathrm{OR}=0.4(0.2-0.7), p=0.001]$, never given birth $[\mathrm{OR}=0.7(0.5-0.9), p=0.045]$, coming from rural informal $[\mathrm{OR}=0.5(0.3-0.9), p=0.010]$ and rural formal settlements $[\mathrm{OR}=0.5(0.3-0.9), p=0.020]$.

Conclusions: Evidence suggest that interventions should be tailor-made to meet the needs of AGYW in order to, promote use and access to contraceptives. The results also suggest that family planning interventions should target those who had not given birth in order to reduce unplanned and or unintended pregnancies and associated risk factors. These findings contribute to public health discourse and reproductive health planning for these age groups in the country.

Keywords: Contraceptive use, Adolescent girls and young women, South Africa, Socio-demographic, Behavioral factors

\footnotetext{
* Correspondence: LMakola@hsrc.ac.za

${ }^{1}$ Social Aspects of Public Health Research Programme, Human Sciences

Research Council, Durban, South Africa

${ }^{2}$ Department of Psychology, University of Limpopo, Polokwane, South Africa

Full list of author information is available at the end of the article
}

(c) The Author(s). 2019 Open Access This article is distributed under the terms of the Creative Commons Attribution 4.0 International License (http://creativecommons.org/licenses/by/4.0/), which permits unrestricted use, distribution, and reproduction in any medium, provided you give appropriate credit to the original author(s) and the source, provide a link to the Creative Commons license, and indicate if changes were made. The Creative Commons Public Domain Dedication waiver (http://creativecommons.org/publicdomain/zero/1.0/) applies to the data made available in this article, unless otherwise stated. 


\section{Background}

The consistent and correct use of contraceptives does not only prevent unplanned and or unintended pregnancies but plays a significant role in reducing maternal morbidity and mortality amongst adolescent girls and young women (AGYW) [1]. It is envisaged that universal access and use of contraceptives amongst AGYW could lead to a decrease of 2.1 million unplanned and or unintended births, 3.2 million abortions, and 5600 maternal deaths each year [2]. Contraceptive use further provides AGYW with an opportunity to make informed decisions about when they want to have their children [3]. Despite these benefits, 214 million women from developing countries had an unmet need of modern contraceptives with approximately 53\% Southern Africa women not using modern contraceptives in 2014 [4]. The 2016 South African Demographic and Health Key Indicators Report also shows that although $58 \%$ of South African women are in use of modern contraceptives, $18 \%$ of them still have unmet need for family planning. An unmet need occurs when a female in her reproductive age is married or unmarried, sexually active and fertile but is not using any method of contraception and does not want to have a child in the next two years or at all [5].

There are several factors predicting none or low usage of contraceptives amongst women. Research evidence has shown that some socio-demographic and behavioral factors influence contraceptive use [6-8]. For example, low contraceptive use has been associated with sociodemographic factors such as women coming from rural areas, those with low educational qualification, low socio-economic status, limited knowledge on accessibility, and awareness of contraceptives [9]. Previous findings also associated poor contraceptive usage with poor knowledge [10]. Furthermore, lack or low contraceptive use was associated with the fear of being labelled wayward and promiscuous for carrying or demanding usage of condoms by their partners [11].

Several behavioral and environmental factors have been suggested to affect correct usage, continuity and method of contraceptives preferred by AGYW. For instance, the age at sexual debut, coerced sexual intercourse, age disparate sexual relationships was associated with influencing contraceptive use [12, 13]. In spite of these factors, the South African government continues to be committed to improving usage of contraceptives. This is in line with global developmental agendas such as Family Planning 2020 and goal no 3.7 of the Sustainable Development Goal (SDG) [14]. In view of these developments and challenges, it is important to have an improved understanding of factors that influence contraceptive use amongst AGYW in order to strengthen current interventions. This paper examines sociodemographic and behavioral predictors of contraceptive use among adolescent girls and young women (AGYW) aged 15 to 24 years using data from the 2012 South African cross-sectional population-based household based survey.

\section{Methods}

\section{Study design and sample}

The analysis used data from the 2012 nationally representative population-based household survey conducted using a multistage stratified design described in detail elsewhere [10]. Briefly, a probability sample of 15 households drawn from 1000 randomly selected randomly selected enumeration areas (EAs) was used. The selection of EAs was stratified by province and locality defined as urban formal, urban informal, rural formal (including commercial farms), and rural informal (including tribal authority areas). In the formal urban areas, race was also used as an additional stratification variable unit. In each sampled household all persons residing in the household were invited to participate [15].

Age specific questionnaires were administered to consenting participants. Respondents were asked about background socio-demographic characteristics, HIV related knowledge, attitudes, and behaviours, reproductive history and contraceptive use. The current analysis focuses on the contraceptive use among a sub-sample of sexually active AGYW aged 15-24 years in relation to socio-demographic and behavioural characteristics. This paper only reports on the 1406 participants that answered questions regarding contraception use.

\section{Measures}

\section{Response variable}

The primary outcome variable for this analysis is women's utilization of any contraceptive method including female sterilization, male sterilization, the pill, the intrauterine device (IUD), injectables, rhythm (periodic abstinence) method, implants, male condom, female condom, withdrawal, emergency pill. The response variable was dichotomized based on a contraception method use question "are you or your partner currently using the following method to prevent pregnancy (yes/no) and the response was coded as 1 if individuals replied that they were using at least one of the above and 0 if they were not using any of the above.

\section{Explanatory variables}

Similar to the explanation provided in another study [16], the explanatory variables used were sociodemographic and behavioural factors. For characterisation of socio-demographics, age was grouped into two categories namely: 15 to 19 years and 20 to 24 years. Race was categorised as follows: Black African or other races - White, Coloured, and Indians or Asians. 
Similarly, marital status was categorised as not married or married, educational level (no education or primary school, secondary school, and tertiary education), employment status (not employed or employed), asset based socio-economic status score (a composite measure based on availability of essential services and ownership of a range of household assets), and locality type (urban formal, urban informal, rural informal, and rural formal).

Behavioural factors included age at sexual debut (younger than 15 or 15 years or older), number of sexual partners in the past year (1 partner, more than 1 partner), Alcohol use risk score (abstainers or low risk users, high risk or hazardous users) based on Alcohol Use Disorder Identification Test (AUDIT) scale, knowledge of HIV (no, yes), self-perceived risk of HIV infection (low, high), awareness of HIV status (yes, no), age of sexual partners (within 5 years, at least 5 years younger, at least 5 years older), ever tested for HIV (yes, no), ever given birth (yes, no), and HIV status (negative, positive).

\section{Statistical analysis}

Descriptive statistics were used to summarize the data. Chi-square analysis was performed to test for differences in proportions of categorical variables. Multivariate backward stepwise logistic regression set at 0.1 was used to determine factors independently associated with contraceptive use. Odds ratios (OR) with $95 \%$ confidence intervals $(\mathrm{CI})$ were used as measures of the direction and strength of the relationships, and a $p \leq 0.05$ was considered statistically significant. All analyses were performed using STATA statistical software version 12.0 (Stata Corporation, College Station, USA).

\section{Results}

\section{Sample characteristics and contraceptive use}

Table 1 describes the study sub-sample and contraceptive use by socio-demographic profile of those individuals who reported sexual activity in the past year. Most participants were aged 20 to 24 years old (70.0\%), were Black Africans (86.4\%), not married (91.0\%), had no education or had primary education only (54.6\%)), were unemployed (81.9\%), were from low SES households (46.6\%), and lived in urban formal settlements (48.1\%).

Table 1 also shows that there was a significant difference in the proportion of Black African (60.2\%; 95\% CI: 55.264.9) individuals that reported using contraceptives compared to other race groups (48.3\%; 95\% CI: 38.3-58.4; $p=$ $0.038)$. They also show that there was a significant difference in the proportion of individuals who reported using contraceptives when comparing individuals from low SES households (66.7\%; 95\% CI: 60.1-72.7), middle SES households (57.1\%; 95\% CI: 50.4-63.5) and high SES households (39.2\%; 95\% CI: 28.8-50.5; $p=0.001$ ).
Table 1 Socio-demographic profile and contraceptive use among adolescent girls and young women (15-24 years)

\begin{tabular}{|c|c|c|c|c|c|}
\hline \multirow[t]{2}{*}{ Variables } & \multicolumn{2}{|c|}{ Study Sample } & \multicolumn{2}{|c|}{ Contraceptive use } & \multirow{2}{*}{$\begin{array}{l}p- \\
\text { value }\end{array}$} \\
\hline & $\bar{N}$ & $\%$ & $\%$ & $95 \% \mathrm{Cl}$ & \\
\hline \multicolumn{6}{|l|}{ Age (years) } \\
\hline 15 to 19 & 424 & 30.0 & 53.7 & $46.4-60.9$ & \multirow[t]{2}{*}{0.117} \\
\hline 20 to 24 & 977 & 70.0 & 60.6 & $55.2-65.8$ & \\
\hline \multicolumn{6}{|l|}{ Race groups } \\
\hline Black African & 1023 & 86.4 & 60.2 & $55.2-64.9$ & \multirow[t]{2}{*}{0.038} \\
\hline Others & 376 & 13.6 & 48.3 & $38.3-58.4$ & \\
\hline \multicolumn{6}{|l|}{ Marital status } \\
\hline Not Married & 1277 & 91.0 & 57.9 & $53.5-62.2$ & \multirow[t]{2}{*}{0.434} \\
\hline Married & 112 & 9.0 & 64.9 & $46.8-79.6$ & \\
\hline \multicolumn{6}{|l|}{ Education level } \\
\hline No education/Primary & 724 & 54.6 & 62.2 & $56.2-67.8$ & \multirow[t]{3}{*}{0.245} \\
\hline Secondary & 479 & 39.4 & 54.1 & $46.8-61.3$ & \\
\hline Tertiary & 63 & 6.0 & 60.0 & $39.8-77.2$ & \\
\hline \multicolumn{6}{|l|}{ Employment status } \\
\hline Unemployed & 1088 & 81.9 & 58.8 & $54.1-63.4$ & \multirow[t]{2}{*}{0.988} \\
\hline Employed & 248 & 18.1 & 58.7 & $47.0-69.6$ & \\
\hline \multicolumn{6}{|l|}{ Asset based SES } \\
\hline LOW SES & 571 & 46.6 & 66.7 & $60.1-72.7$ & \multirow[t]{3}{*}{0.001} \\
\hline Middle SES & 551 & 33.1 & 57.1 & $50.4-63.5$ & \\
\hline High SES & 253 & 11.9 & 39.2 & $28.8-50.5$ & \\
\hline \multicolumn{6}{|l|}{ Locality type } \\
\hline Urban formal & 685 & 48.1 & 54.7 & $47.9-61.2$ & \multirow[t]{4}{*}{0.124} \\
\hline urban informal & 217 & 8.8 & 63.5 & $53.3-72.6$ & \\
\hline rural informal & 389 & 39.3 & 63.2 & $55.8-70.0$ & \\
\hline rural formal & 110 & 3.8 & 48.0 & $31.0-65.5$ & \\
\hline
\end{tabular}

*Not all sub-total add to the overall totals due to non-response and missing data, SES socio-economic status, $\mathrm{Cl}$ confidence intervals

Table 2 describes the study sample and contraceptive use by behavioural factors amongst AGYW who reported sexual activity in the previous year. Most of the participants had sexual debut at age 15 years or older (95.1\%), had one sexual partners in the previous year (952.3\%), had a sexual partner aged within 5 years of their age (65.1\%), were abstainers/low risk alcohol users (90.3\%), had never given birth (58.4\%), had correct knowledge of HIV (50.7\%), believed they were at a low risk of HIV infection (69.6\%), and ever tested for HIV (82.3\%).

Table 2 also shows that there was a significant difference in the proportion of individuals who reported using contraceptives when comparing those who had given birth before (68.7\%; 95\% CI: 63.1-73.8) and those who had never given birth (44.3\%; 95\% CI: 38.0-50.9; $p<0.001)$. There was also a significant difference in the proportion of individuals who reported using 
Table 2 Behavioural factors and contraceptive use among adolescent girls and young women (15-24 years)

\begin{tabular}{|c|c|c|c|c|c|}
\hline \multirow[t]{2}{*}{ Variables } & \multicolumn{2}{|c|}{ Study sample } & \multicolumn{2}{|c|}{ Contraceptive use } & \multirow[b]{2}{*}{ p-value } \\
\hline & $\mathrm{N}$ & $\%$ & $\%$ & $95 \% \mathrm{Cl}$ & \\
\hline \multicolumn{6}{|l|}{ Age at sexual debut } \\
\hline Younger than 15 & 77 & 4.9 & 61.2 & $45.1-75.3$ & \multirow[t]{2}{*}{0.755} \\
\hline 15 years and older & 1273 & 95.1 & 58.7 & $54.1-63.2$ & \\
\hline \multicolumn{6}{|c|}{ Sexual partners in the last 12 months } \\
\hline 1 partner & 1087 & 92.3 & 60.9 & $55.9-65.7$ & \multirow[t]{2}{*}{0.200} \\
\hline $2+$ partners & 102 & 7.7 & 51.7 & $38.0-65.2$ & \\
\hline \multicolumn{6}{|l|}{ Age of Sexual Partner } \\
\hline Within 5 years & 754 & 65.1 & 62.4 & $56.6-67.9$ & \multirow[t]{3}{*}{0.344} \\
\hline Five years younger & 1 & 0 & 100 & & \\
\hline Five years older & 430 & 34.9 & 57.6 & $49.5-65.2$ & \\
\hline \multicolumn{6}{|l|}{ Alcohol use risk score (AUDIT) } \\
\hline Abstainers/low risk users & 1115 & 90.3 & 59.7 & $54.9-64.2$ & \multirow[t]{2}{*}{0.387} \\
\hline High risk/hazardous users & 110 & 9.7 & 50.8 & $31.6-69.7$ & \\
\hline \multicolumn{6}{|l|}{ Ever Given Birth } \\
\hline Yes & 790 & 58.4 & 68.7 & $63.1-73.8$ & \multirow[t]{2}{*}{$<0.001$} \\
\hline No & 583 & 41.6 & 44.3 & $38.0-50.9$ & \\
\hline \multicolumn{6}{|l|}{ Correct Knowledge of HIV } \\
\hline No & 702 & 49.3 & 60.7 & $54.5-66.6$ & \multirow[t]{2}{*}{0.306} \\
\hline Yes & 693 & 50.7 & 56.3 & $50.2-62.3$ & \\
\hline \multicolumn{6}{|c|}{ Self-perceived risk of HIV Infection } \\
\hline Low & 413 & 30.1 & 69.5 & $61.7-76.3$ & \multirow[t]{2}{*}{$<0.001$} \\
\hline High & 979 & 69.9 & 53.7 & $48.5-58.9$ & \\
\hline \multicolumn{6}{|l|}{ Ever Tested for HIV } \\
\hline Yes & 1152 & 82.3 & 62.9 & $58.1-67.5$ & \multirow[t]{2}{*}{$<0.001$} \\
\hline No & 246 & 17.7 & 38.1 & $28.6-48.6$ & \\
\hline \multicolumn{6}{|l|}{ Awareness of HIV status } \\
\hline Yes & 847 & 62.7 & 62.7 & $57.3-67.7$ & \multirow[t]{2}{*}{0.007} \\
\hline No & 534 & 37.3 & 51.6 & $44.7-58.4$ & \\
\hline \multicolumn{6}{|l|}{ HIV Status } \\
\hline Negative & 1013 & 83.5 & 59.1 & $53.9-64.1$ & \multirow[t]{2}{*}{0.570} \\
\hline Positive & 171 & 16.5 & 62.3 & $51.7-71.8$ & \\
\hline
\end{tabular}

*Not all sub-total add to the overall totals due to non-response and missing data, $\mathrm{Cl}$ confidence intervals, AUDIT Alcohol Use Disorder Identification Test

contraceptives when comparing those who believed that they were at a low risk of HIV infection (69.5\%; 95\% CI: $61.7-76.3)$ and those who believed that they were at a high risk of HIV infection (53.7\%; 95\% CI: 48.5-58.9; $\mathrm{p}<0.001$ ). There was a significant difference in the proportion of individuals who reported using contraceptives when comparing those who reported that they had previously tested for $\mathrm{HIV}$ (62.9\%; 95\% CI: 58.1-67.5) and those who had never tested for HIV (38.1\%; 95\% CI: $28.6-48.6 ; \mathrm{p}<0.001)$. Finally, there was a significant difference in the proportion of individuals who reported using contraceptives when comparing those who were aware of their HIV status (62.7\%; 95\% CI: 57.3-67.7) and those who had never tested for HIV (51.6\%; 95\% CI: $44.7-58.4 ; p=0.007$ ).

\section{Types of contraceptives used}

Figure 1 below shows that $1 \%$ of women reported that they were sterilized, $1 \%$ of females reported that their partner was sterilized, $9.6 \%$ of females reported that they were on the pill, $2.3 \%$ reported that they had an intrauterine device, $34.8 \%$ reported that they were using injectables, 3.3\% reported that they were using the rhythm method, $6.3 \%$ reported that they were using the withdrawal method, $1 \%$ reported that they used the emergency contraception, and $40.6 \%$ reported using condoms.

\section{The multivariate regression model}

The multivariate analysis (Fig. 2) shows that contraceptive use was significantly more likely among participants who had a secondary education compared to those with no education or primary level education $[\mathrm{OR}=1.8$ (95\%CI: 1.2-2.7), $p=0.005]$. The increased likelihood of using contraception was also partially significant among those with tertiary education [OR $=2.7$ (95\%CI: 0.9-7.3), $p=0.055]$. In addition, participants with sexual partners within 5 years of their age were significantly more likely to use contraceptives than those who had sexual partners that were 5 years older than them $[\mathrm{OR}=1.8$ (95\%CI: $1.2-2.5), p=0.002$ ]. Participants who had their sexual debut at age 15 years or older were significantly more likely to use contraceptives than those who had their sexual debut before the age of 15 years $[\mathrm{OR}=2.5$ (95\%CI: 1.3-4.6), $p=.006]$.

Furthermore, participants of other race groups were significantly less likely to use contraceptives when compared to Black Africans [OR $=0.5$ (95\%CI: 0.3-0.7), $p=$ 0.001]. Married individuals were significantly less likely to use contraceptives when compared to their unmarried counterparts [OR $=0.4$ (95\%CI: 0.2-0.7), $p=0.001$ ]. Participants that had never given birth were significantly less likely to use contraceptives compared to participants who had ever given birth [OR $=0.7$ (95\%CI: 0.5-0.9), $p=0.045]$. Contraceptive use was also significantly less likely among participants from rural informal $[\mathrm{OR}=0.5$ (95\%CI: 0.3-0.9), $p=0.010$ ] and rural formal settlements $[\mathrm{OR}=0.5$ (95\%CI: 0.3-0.9), $p=0.020]$ compared to those from urban formal settlements.

\section{Discussion}

The findings of this nationally representative survey suggest that there are socio-demographic and behavioral factors influencing the use of contraceptives. For socio-demographic factors, important predictors of contraceptive use among 


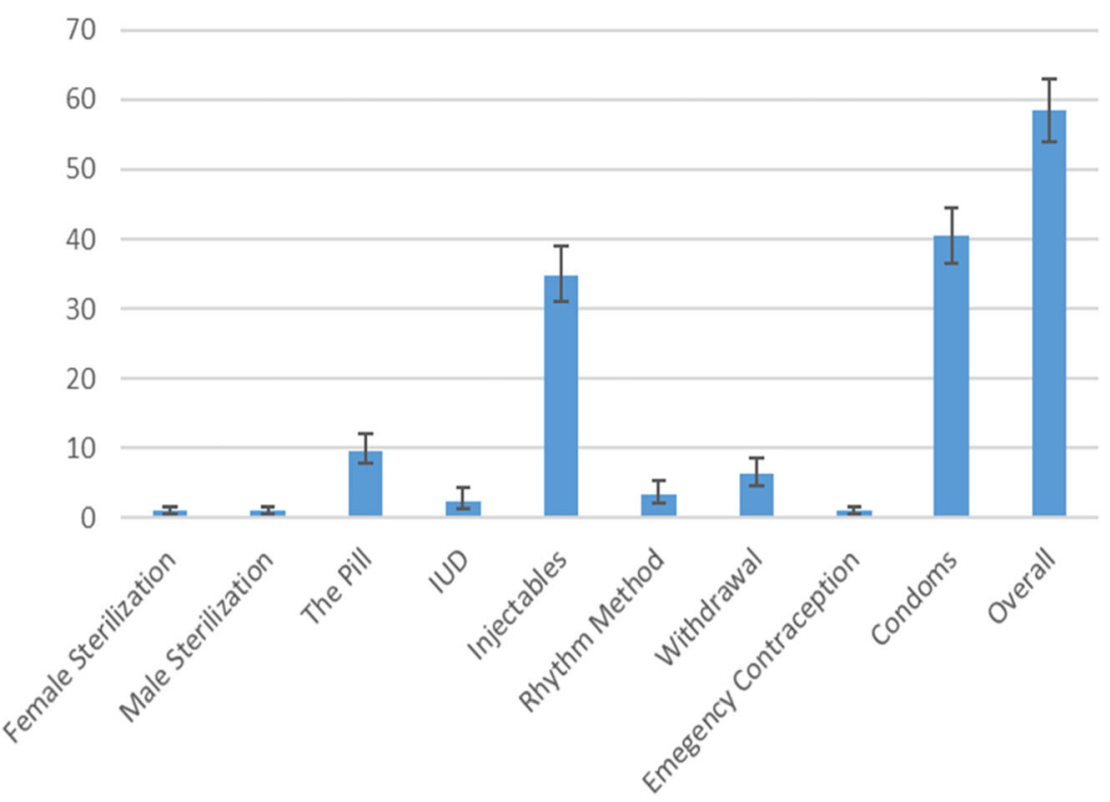

Fig. 1 Types of contraceptives used by AGYW

AGYW were educational level, locality type and marital status. Similarly, other studies also found that contraceptive use was higher among young women with secondary and tertiary education compared to those with primary education [9, 17]. Education exposes women to reproductive health information and empowers them to make informed decisions about reproductive health and methods available for them [18]. It is important for policy makers to develop interventions targeting on the differences in the subgroups of women.
In line with the current findings, other studies also found that young women from rural informal and formal settlements were less likely to use contraception compared to those from urban formal settlements $[19,20]$. This has been attributed to limited awareness of contraceptive methods available to them and challenges with access to health care services [21]. It is particularly concerning that family planning remains a challenge to many rural AGYW in the country despite policy and interventions aimed at improving sexual and reproductive

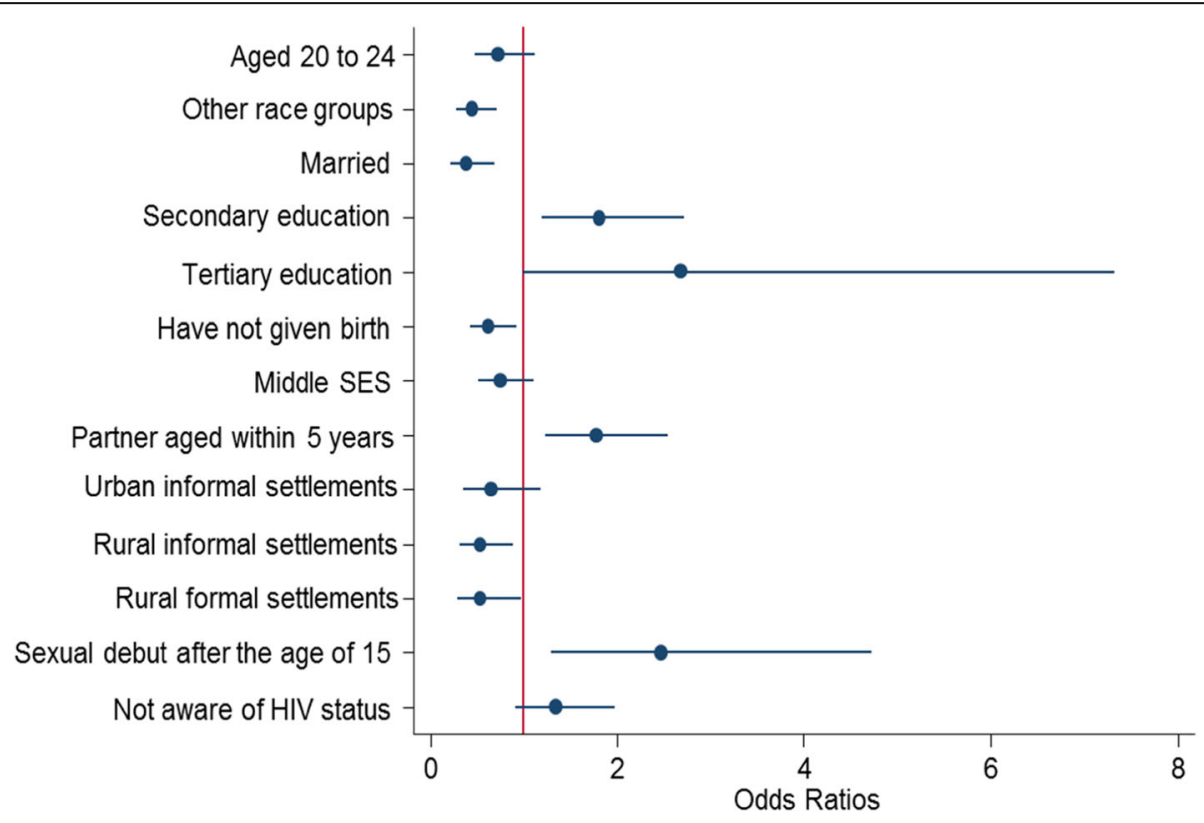

Fig. 2 Multivariate model of factors associated with contraception use 
health information [22]. It is therefore important to improve accessibility to contraceptives through improving awareness on the types of contraceptives available, benefits of using them and access of contraceptives. The relationship between nursing staff at the clinics and young girls should also be friendly and non-judgemental environment. Stereotypes towards contraceptives should be addressed in order to encourage use.

Also amongst socio-demographic factors, marriage was also associated with non-use of contraceptive. This finding was previously linked to the desire to have children within marriage, cultural norms or opposition by the husbands [23, 24, 7]. This finding could also suggest that the majority of unmarried AGYW are using contraceptives. This has positive implications since prevention of unintended pregnancy is considered a priority among policymakers and the public because of its high economic, social and health costs for young people and their families $[25,26]$.

Furthermore, among behavioral factors the results showed that important predictors of contraceptives use among AGYW were age at sexual debut, partner age difference and child bearing. The findings imply low contraceptive use amongst those who had sexual debut before the age of 15 years. Similarly, a previous study supports this finding [27]. The lack of contraceptive use amongst those who had sex before age 15 could be linked to lower knowledge and fear to access contraceptives at their age due to societal stigma. In addition, the perception that being exposed to contraceptives at an early age encourages adolescents to engage in sexual activities may be a hindrance to early initiation to contraceptives by both adolescents and parents $[20,28]$. Others have shown that sexual debut at 14 year and younger without use of contraceptives was a strong predictors of the likelihood of inconsistent usage of contraceptives even in later sexual engagements [20].

The findings further suggest that having a sexual partner 5 years and older is associated with low contraceptive use compared to having a sexual partner within one's age. Epidemiologic studies of relationships and contraceptive use have demonstrated a strong association between relationship type, and contraceptive decision-making including condom use [26]. For example, evidence shows that condom use is negotiable when the age range between partners is within 5 years, and this has been linked to gender-power dynamics [26, 29-32]. The results also showed that contraceptive use was less likely among AGYW who had not given birth as observed in other studies [33]. Family planning interventions should be tailored to target these specific groups of women.

\section{Limitations}

This study has some limitations and should be should also be interpreted with caution. First, the data is based on cross-sectional design and, therefore cannot be used to infer causality. In addition, the analysis was based on self-reported information that may be influenced by recall and social desirability bias. Nevertheless, this paper provides an insight into the predictors of contraceptive usage amongst adolescent girls and young South African women (15-24 years) using nationally representative data. Therefore, the findings of this study contributes to public health discourse and reproductive health planning for AGYW.

\section{Conclusion}

The findings highlights a need to promote the availability and acceptability of the different contraceptives for use by AGYW. There is need to improve awareness on family planning services and increase access to contraceptives where needed. It further calls for the reinforcement of a non-judgmental environment in health facilities. Interventions should be tailor made and incorporate peer-mediated interventions because of the differences in women according to their educational level, place of residence, and marital status. There is also a need for age specific message to prevent and or delay early sexual debut and unplanned pregnancies until adolescents and young women have sufficient information and can thus make informed decision regarding their sexuality and fertility. Partners especially males have been associated with low usage of contraceptives amongst women. This is a clear indication that barrier methods is not just a 'woman problem' and although she often bares the consequences of an unplanned pregnancy, their male partners have significant influence in whether they use contraceptives or not. Thus, not only do policy makers and interventions need peer-mediated and fit-for-purpose interventions, it is critical that males are made part of the discourse and solution for the utilization of contraceptive methods.

\section{Abbreviation \\ AGYW: Adolescent girls and young women}

\section{Acknowledgements}

We would like to thank South Africans who participated in the study.

\section{Authors' contributions}

LM drafted the manuscript. MM and KZ contributed to the conception, design and acquisition of data. LLM and MM participated in data analysis, interpretation and reviewed the final version. CB, ZS, ZS, LS, NDKS, MS made a significant contribution to the manuscript. All authors read and approved the final manuscript.

\section{Funding}

This study has been supported by the President's Emergency Plan for AIDS Relief (PEPFAR) through the Centers for Disease Control and Prevention (CDC) under the terms of 5 U2GGH000570. The contents of this paper are 
solely the responsibility of the authors and do not necessarily represent the official views of CDC.

\section{Availability of data and materials}

The dataset(s) could be available through the Human Sciences Research Council data research repository via access dataset http://www.hsrc.ac.za/en/ research-data/ upon request.

\section{Ethics approval and consent to participate}

Ethical approval for the study was obtained from the Human Sciences Research Council (HSRC') Research Ethics Committee (REC: 5/17/11/10) as well as from the Associate Director of Science of the National Center for HIV and AIDS, Viral Hepatitis, STD and TB Prevention at the Centers for Disease Control and Prevention (CDC) in Atlanta, USA.

\section{Consent for publication}

Not applicable.

\section{Competing interests}

The authors declare that they have no competing interests.

\section{Author details}

${ }^{1}$ Social Aspects of Public Health Research Programme, Human Sciences Research Council, Durban, South Africa. ${ }^{2}$ Department of Psychology, University of Limpopo, Polokwane, South Africa. ${ }^{3}$ Department of Psychology, University of KwaZulu-Natal, Durban, South Africa. ${ }^{4}$ Critical Studies in Sexualities and Reproduction, Rhodes University, Makhanda, South Africa. ${ }^{5}$ Human and Social Development, Human Sciences Research Council, Durban, South Africa.

Received: 17 September 2018 Accepted: 1 December 2019 Published online: 12 December 2019

\section{References}

1. Feucht UD, Meyer A, Kruger M. Missing HIV prevention opportunities in south African children-a 7-year review. BMC Public Health. 2014;14(1):1265.

2. Darroch JE, Woog V, Bankole A, Ashford LS. Adding it up: costs and benefits of meeting the contraceptive needs of adolescents. 2016.

3. Michalow J, Chola L, McGee S, Tugendhaft A, Pattinson R, Kerber K, et al. Triple return on investment: the cost and impact of 13 interventions that could prevent stillbirths and save the lives of mothers and babies in South Africa. BMC Pregnancy Childbirth. 2015;15(1):39.

4. Singh S, Bankole A, Darroch JE. The impact of contraceptive use and abortion on fertility in sub-Saharan Africa: estimates for 2003-2014. Popul Dev Rev. 2017:43(S1):141-65.

5. Sedgh G, Ashoford LS, Hussain R. Unmet need for contraception in developing countries: examine women's reasons for not using a method. The Guttmacher Institute, 2016

6. Bjelica A. Socio-demographic factors influence contraception use among female students of the University of Novi sad (Serbia). The Eur J Contracept Reprod Health Care. 2008;13(4):422-30.

7. Solanke BL. Factors influencing contraceptive use and non-use among women of advanced reproductive age in Nigeria. J Health Popul Nutr. 2017;36(1):1

8. Blackstone SR, Iwelunmor J. Determinants of contraceptive use among Nigerian couples: evidence from the 2013 demographic and health survey. Contracept Reprod Med. 2017;2(1):9.

9. Christofides NJ, Jewkes RK, Dunkle KL, Nduna M, Shai NJ, Sterk C. Early adolescent pregnancy increases risk of incident HIV infection in the Eastern Cape, South Africa: a longitudinal study. J Int AIDS Society. 2014;17(1).

10. Rios-Zertuche D, Blanco LC, Zúñiga-Brenes P, Palmisano EB, Colombara DV, Mokdad AH, Iriarte E. Contraceptive knowledge and use among women living in the poorest areas of five Mesoamerican countries. Contraception. 2017:95(6):549-57.

11. Ochako R, Mbondo M, Aloo S, Kaimenyi S, Thompson R, Temmerman M, Kays M. Barriers to modern contraceptive methods uptake among young women in Kenya: a qualitative study. BMC Public Health. 2015;15(1):118.

12. Toska E, Cluver LD, Boyes M, Pantelic M, Kuo C. From 'sugar daddies' to 'sugar babies': exploring a pathway among age-disparate sexual relationships, condom use and adolescent pregnancy in South Africa. Sex Health. 2015;12(1):59-66.
13. Digitale J, Psaki S, Soler-Hampejsek E, Mensch BS. Correlates of contraceptive use and health facility choice among young women in Malawi. The ANN Am Acad Pol Soc Sci. 2017;669(1):93-124.

14. WHO U, Mathers C. Global strategy for women's, children's and adolescents' health (2016-2030). Organization. 2017;2016(9).

15. Shisana O, Rehle T, Simbayi LC, Zuma K, Jooste S, Zungu N, et al South African national HIV prevalence, incidence and behaviour survey, 2012. 2014.

16. Mlangeni L, Makola L, Naidoo I, Chibi B, Sokhela Z, Silimfe Z, Mabaso M. Factors associated with physical activity in South Africa: evidence from a National Population Based Survey. The Open Public Health J. 2018;11(1).

17. Nyarko SH. Prevalence and correlates of contraceptive use among female adolescents in Ghana. BMC Womens Health. 2015;15(1):60.

18. Tekelab T, Melka AS, Wirtu D. Predictors of modern contraceptive methods use among married women of reproductive age groups in Western Ethiopia: a community based cross-sectional study. BMC Womens Health. 2015;15(1):52.

19. Akokuwebe ME, Ojo OA. Factors influencing acceptability of family planning among women in rural communities in Ife central local government area, Osun state. Nigeria.

20. Jacobs P, Makaudze E. Understanding rural livelihoods in the west coast district. South Afr Dev South Afr. 2012;29(4):574-87.

21. Peer N, Morojele N, London L. Factors associated with contraceptive use in a rural area in Western Cape Province. SAMJ. 2013;103(6):406-12.

22. Dickson KE, Ashton J, Smith J-M. Does setting adolescent-friendly standards improve the quality of care in clinics? Evidence from South Africa. Int J Qual Health Care. 2007;19(2):80-9.

23. Yadav $K$, Agarwal $M$, Singh JV, Singh VK. Determinants of non-use of family planning methods by young married women (15-24 years) living in urban slums of Uttar Pradesh. Indian J Community Health. 2017;29(1):55-66.

24. Shree V, Prasad R, Kumar S, Sinha S, Choudhary SK. Factors for non-acceptance of contraceptive methods amongst married women of reproductive age group in rural Patna. Int J Community Med Public Health. 2017;4(6):1882-7.

25. Sonfield A, Kost K. Public costs from unintended pregnancies and the role of public insurance programs in paying for pregnancy-related care. National State Estimates for 2010. 2015:2015

26. Yazdkhasti M, Pourreza A, Pirak A, Abdi F. Unintended pregnancy and its adverse social and economic consequences on health system: a narrative review article. Iran J Public Health. 2015:44(1):12.

27. Seutlwadi L, Peltzer K, Mchunu G, Tutshana BO. Contraceptive use and associated factors among South African youth (18-24 years): A populationbased survey. South Afr J Obstet Gynaecol. 2012;18(2).

28. Finer LB, Philbin JM. Sexual initiation, contraceptive use, and pregnancy among young adolescents. Pediatrics. 2013;131(5):886-91.

29. Raine TR, Gard JC, Boyer CB, Haider S, Brown BA, Ramirez Hernandez FA, et al. Contraceptive decision-making in sexual relationships: young men's experiences, attitudes and values. Culture Health Sexuality. 2010;12(4):373-86.

30. Beauclair R, Dushoff J, Delva W. Partner age differences and associated sexual risk behaviours among adolescent girls and young women in a cash transfer programme for schooling in Malawi. BMC Public Health. 2018;18(1):403.

31. Brouard $P$, Crewe M. Sweetening the deal? Sugar daddies, sugar mummies, sugar babies and HIV in contemporary South Africa. Agenda. 2012;26(4):48-56.

32. Ritchwood TD, Hughes JP, Jennings L, MacPhail C, Williamson B, Selin A, et al. Characteristics of age-discordant partnerships associated with HIV risk among young South African women (HPTN 068). J Acqui Immune Defic Syndr (1999). 2016;72(4):423.

33. MacPhail C, Pettifor AE, Pascoe S, Rees HV. Contraception use and pregnancy among 15-24 year old south African women: a nationally representative cross-sectional survey. BMC Med. 2007:5(1):31.

\section{Publisher's Note}

Springer Nature remains neutral with regard to jurisdictional claims in published maps and institutional affiliations. 